SCIREA Journal of Education

http://www.scirea.org/journal/Education

November 16, 2021

SCIREA

Volume 6, Issue 6, December 2021

\title{
Design Thinking for Online Instruction in India
}

\author{
Pamila Dembla ${ }^{1, *}$, Yash Nihal Rajpal², Hersh Mathur ${ }^{3}$ \\ ${ }^{1}$ Information Systems and Security, Kennesaw State University, Kennesaw, USA \\ ${ }^{2}$ Downington East High School, Exton, USA \\ ${ }^{3}$ Campbell High School, Marietta, USA \\ *Corresponding author: pdembla@kennesaw.edu
}

\begin{abstract}
India is the second most populous nation in the world and has been greatly impacted by COVID-19 causing extensive damage in terms of death as well as living conditions. Aside from health and economic consequences, COVID-19 has affected the education sector as well. As a result of lockdowns and social distancing mandates, students were unable to attend school and colleges and had to depend on technology for their education. Many schools were unprepared. Some schools did not have the financial resources for technology and their teachers were not adequately trained to instruct online. The purpose of this paper is to discuss the implementation of design thinking methodology for providing a faculty and student driven solution for online instruction in a suburban low-income school in India. This paper explains the process of understanding the issues affecting online education in India and training 90 faculty to successfully instruct online. Lack of internet connectivity and affordable technology are major hindrances for education in India.
\end{abstract}

Keywords: India, Covid-19, online education, design thinking 


\section{Introduction}

India, being the second most populated country and the world's largest democracy, has always been a center for advanced education, at least for those fortunate enough to be able to afford the costs associated with quality education. Its educational system has helped to shape and create some of the world's most academically advanced students, leading to India becoming a hub for technological and infrastructural advancement. Considering its increasing poverty rate and decreasing middle class [6], India has managed to maintain an average literacy rate of 74.04 percent [10]. However, this already below average percentage was further decreased by the COVID-19 crisis. This pandemic devastated economies around the globe because of its impact on various industries, such as travel, hospitality, sports, financial markets, entertainment, and education. As for its economic impact, COVID-19 caused a 3\% decrease in the world annual GDP, and a 7.4\% decrease in the India's GDP in 2020 alone. Many of the world's most advanced and developed economies such as Italy, Germany, Japan, and the United Kingdom saw sharp decreases in their annual GDP in 2020 as well, making this one of the worst economic depressions in history since the stock market crash of 1929, also known as the Great Depression [21]. The implementation of quarantines, social distancing mandates, and safety measures to prevent the spread of COVID-19 completely disrupted the global economy.

Aside from its economic consequences, COVID-19 caused devastation in terms of deaths as well. Beginning in the meat markets of Wuhan, China, the virus spread throughout the world quickly, in a matter of weeks. It was officially declared a pandemic on March $11^{\text {th }}, 2020$, by the World Health Organization, and reached around 181 million confirmed cases and 3.9 million deaths worldwide as of June 2021 [17]. Especially in developing countries, by interrupting the chains of production in both agriculture and manufacturing, COVID-19 created terrible living situations for those who were already struggling to feed their families and to provide basic necessities needed for living. Price of food increased by as much as $19.5 \%$ in some developing countries, because of the disruption of production/cultivation of crops due to COVID-19. Increased demand and decreased supply of food meant that a food shortage was inevitable, and many impoverished people around the globe suffered from a lack of food and water. Additionally, the disproportional distribution of COVID vaccines between wealthier and developing nations allowed the virus to continue spreading throughout thirdworld countries. For example, despite only making up to $16 \%$ of the world population, wealthy/developed countries bought more than half of the COVID-19 vaccine supply [21]. 


\subsection{Impact of COVID on Education in India}

The implementation of quarantines, social distancing mandates, and safety measures to prevent the spread of COVID-19 completely disrupted the business and the education sector. People had to depend on ICT's (Information and Communication Technologies) for work, education, and even social interaction. At least 290.5 million students across the globe had an interrupted education because of COVID-19, because of schools closing to comply with social distancing mandates [17]. The main issue in education caused by COVID-19 was that students could no longer go to school in person. They had to rely on ICT's to have access to teachers and the learning environment.

In countries in South Asia, such as India and Sri Lanka, internet availability is lacking: many families in the slums of New Delhi, for example, lack such technology [12]. This presented a problem during a pandemic like Covid-19 on issues such as distribution of information and safety guidelines, but even more than that, technology is important as it is becoming more and more integrated in our daily life. People's access to technology must be increased for a true globalized economy. One of the largest problems for underdeveloped countries during this crisis that also affected a large portion of the population was education. As a result of the pandemic, schools across the country were unable to continue normal education procedures, which undoubtedly pushed children farther and farther behind in the curriculum. This paper will evaluate the aspects of education in the coronavirus pandemic in India.

One of the first problems that arose with the need for online education in India was the lack of technology provided to Indian citizens. It elicits the question: how are educators supposed to do their jobs without means of communication with their students? The effects of socioeconomic downturn in rural areas of India and their lack of access to substantial technology becomes one of the largest factors of concern for educators. However, access to technology is possible: in one study, researchers provided multiple scenarios for providing broadband networks to rural communities in India [19]. Although the cost was high, providing such options to rural communities allowed them to grow and make up for the cost. Although providing technology access is quite important, one must consider the accessibility of technology support for those who have never used such technology before. In a study published in the British Journal of Educational Technology, researchers conducted an experiment to determine whether children can learn technology independent of parental guidance; in the end, students were able to understand the technology and use it effectively. Their knowledge of technology, however, was limited to no previous exposure. This indicates 
that technology proficiency takes no teacher: instead, students can learn because of simple exposure and experimentation [12].

Of course, one must also consider the extent to which accessibility to technology is already present compared to the rest of the world. India has made an effort to provide communications technology to many areas, but it is still lacking. According to the International Telecommunication Union, India ranks 121st in the world in terms of development of communications technology, 122nd in the world in terms of access, and 117th in the world in terms of communication skills [14]. Compared to developed countries such as Korea, Sweden, Iceland, and the United States, India falls behind on most metrics related to technology. India, in other words, does not have the same capabilities to stay connected during a pandemic such as Covid-19. According to a study from the London School of Economics and Political Science, "attacking poverty" identifies three priority areas for reducing poverty: increasing opportunity, enhancing empowerment, and improving security [2]. One of the main pathways to achieve these goals is providing access to technology. Three projects that stood out from the study included computerized milk centers, smart cards, and the India Healthcare Delivery project. Each project provided the industry with access to technology, which ultimately benefited employees by providing them with a clearer and more efficient system [2]. Today, however, the pandemic presented a problem for another large industry: education.

Online education has started to propagate throughout India in the light of the coronavirus pandemic; as a result, digital education is growing at a rate faster than in other countries. However, the lack of technology in India presents another issue: how to get education to those families who do not have access to laptops or desktops. Compared to the United States, only the richest populations in India have access to computers that have speeds high enough to access educational platforms [20]. Given the vast necessity to educate their students during COVID-19 in the fall session, education systems had to prepare for a worst-case scenario: online education. As a result, new platforms including Google Classroom and local platforms are gaining ground. Countries and their populations needed to assess whether they would be able to continue with the current mode of education and whether it would be sufficient to educate the students in grade schools.

Certainly, students felt affected by the immediate toll that coronavirus had on the education system. In a study conducted in the International Journal of Research and Review, ninety percent of graduate and postgraduate students felt that coronavirus has had a huge impact on 
education. Furthermore, many students felt that it was harder to focus on studies and that expenditure would increase during and after the pandemic [5]. Of course, online education, even with its downsides, provides an alternative to in-class instruction since the pandemic extended into the school year. Even in terms of higher education, coronavirus crippled Indian students' ability to travel to their destinations: according to one study, typically three in four students head to five international destinations for their higher education. Yet, due to the coronavirus, they were unable to. At the same time, immigration and employment were at alltime lows due to the many restrictions on travel faced by international students. It turns out, the study cites, that the only alternatives to such international institutions were those already existing in India [7]. The problem, then, was their accessibility to online education resources. Thanks to India's technological capabilities, it was able to provide much needed resources to at least part of its population. However, its use of technology in its educational system has been difficult to implement and has not been entirely successful.

India is on the lower side of the literacy rate spectrum with a total literacy rate of 74.04, as compared to China (90.9) or Russia (99.4). This relatively low literacy rate has been rising steadily, but not fast enough to catch up with the world's technological advances. One major reason for this is that as the children in more rural areas get older, they drop out of school and never finish their education to help provide for their families in order for them to survive. According to one survey taken in India in 2007, 93.4 percent of all children ages 6-14 were enrolled in a school, but for older students, enrollment rate was significantly lower, especially for boys. As of 2006, India's literacy rate was 61.1, and as of 2020 is 71.2 [23]. However, despite these 10 points nationwide increase in literacy, this number is still very low compared to other countries that share the same technological capabilities that India does.

Even though many areas are lacking, some of India's most urban areas are well equipped with online learning tools. Common in universities, online tools such as Byju and Vedantu are available for younger students, and the market for online educational programs in India has been expanding rapidly over the past decade. For example, India's online education market was worth about \$247 million in 2016 and is expected to grow to \$1.96 billion in 2021 [13]. Because of this rise in online educational material, many students have been able to use this to educate themselves at home if going to school is not a good option for them. This is a big step forward for Indian education, as it could, in the future, eliminate the need for children to have to learn in poorly built and maintained schools. 
There are, however, several major problems with implementing online education in Indian school systems. One major issue is obvious: many people simply cannot pay for the materials needed for effective online learning. Those living in poverty cannot afford things like a stable Wi-Fi connection, a phone/laptop, etc., and even if they did gain access to such resources, they most likely would not have the technical knowledge to understand how to operate such devices. Also, if people in closed, tight-knit villages and impoverished areas could afford to have these technologies, many may become more resistant towards adapting to new changes. These villages tend to be much more conservative, and younger generations are generally taught by the elders. Any new implementation of new technology could completely change their traditional way of life. Both of these issues stem from the social disparities between the impoverished, the middle class, and the rich. Because of the huge disproportion between each group in India, what may benefit one group could be horrible for the other. The middle class and the impoverished make up such a huge percentage of India's population, and while people in the middle class and in the rich elite can afford reliable internet and devices, those in poverty cannot [18].

Even before the coronavirus outbreak, the government, and an assortment of EdTech companies were taking the role as leaders in alternative education. As experts [1] suggest, "EdTech is being considered and adopted by the central and state governments to improve elementary education by potentially solving systemic issues like reach, equity, and quality". Regardless of the distribution of such technology, however, problems exist with its implementation during the coronavirus outbreak. For this reason, a research study is required to decipher the way that schools without independent funding for technology will provide education to their students.

In recent years, improvement in ICTs has greatly impacted the way in which content is taught, as well as the type of content taught. According to [16] at Edith Cowan University, the development of ICTs and their integration into society has impacted the scope of educational content by normalizing "competency and performance-based curricula" [16]. In other words, the increased use of ICT supports the teaching of content that requires lots of sources, student driven learning, and problem-solving based educational exercises. Additionally, [16] argues that the increase in ICTs, especially the internet and the growing normalcy of home computers, allows for the development of student-centered learning. With ICTs at their disposal, it was now possible for students to discover and understand information at their own time and pace with access to millions of sources, changing the education sector forever. This is shown in a 
study done by [15]. He studied 17 kindergarten programs in Greece and the role that ICT played in those classrooms. The study took place for around a year and a half in 2009-2010, and each time a child used the computer located in the classroom, it was recorded and categorized into several reasons why the computer was being used. At the end of the study, it was found that one of the top reasons for using the computer was to develop language and fine motor skills [15]. In this way, it is shown that ICTs are taking precedence in the teaching of essential skills, and thus are becoming much more commonly used in education. However, as previously mentioned, the increased normalization of ICTs in education means that underdeveloped countries with weaker infrastructure (and thus less ICTs) suffer more due to unequal wealth distribution.

During COVID-19, in order to continue their education and not miss out on valuable learning, students were expected to have some kind of electronic device with a stable internet connection. This would make it possible for teachers to send out lessons through email or virtual classrooms or organize virtual class sessions over platforms such as Zoom and Google Meets. While this was not a big problem for developed countries, developing nations like India struggled to be able to continue online education since a large portion of the population did not have access to the technology needed to continue. As the COVID-19 period progressed, it was realized that there were only a small percentage of students from upper-and middle-class families who were actually able to afford access to a quality education through an online platform. This huge economic disparity between the rich, the middle class, and the poor became a big problem in the implementation of online learning in India. The scope of the gap between India's richest and most impoverished is shown by the fact that the top $10 \%$ of India's upper-class control over 3 quarters of the national wealth, while the poorer part of the population (around 67 million people) was only able to increase their earnings by 1 percent [4]. Since this huge social disparity exists, students who go to a certain school may not all have the same tools and resources required for an online curriculum. Because of the sudden and immediate switch to a remote setting that requires these devices, many of the more impoverished people were not able to continue their education. No one had known that COVID-19 would cause all of these infrastructural systems to essentially shut down, so people who did not already own some kind of electronic device were completely blindsided and immediately pushed into a situation that they were not financially prepared for.

In other words, many people living in poverty could not pay for the materials needed for effective online learning during the pandemic. Many of them could not afford things like a 
stable Wi-Fi connection and a phone/laptop. Additionally, even if they managed to gain access to those tools, they most likely would not have had the technical know-how to understand how to operate them or understand basics such as what to do if the Wi-Fi stopped working, or how to download apps. Add to that the difficulty of transporting and providing technologies and devices to remote, rural areas. Secluded areas further away from urbanized areas are much harder to reach. It is difficult to deliver the necessary equipment to these areas, so there are several geographical barriers, in addition to the technical ones. It can be especially difficult to implement things like Wi-Fi or telephone lines near unreachable villages or near natural signal barriers like mountains, hence those areas may not be able to have access to the necessities required for online education. Furthermore, India's Internet infrastructure is not developed enough to provide a reliable source of network signal that the students need to attend classes, according to a report done by Quacquarelli Symonds, a university/school ranking committee [13]. This report found that, even among students who had a secure home broadband Wi-Fi connection, over half of them constantly faced poor connectivity issues. Those that used mobile hot spots or Wi-Fi dongles more often faced power issues as well [13]. This showcases another struggle with the current online education system in India, as it does not have a fully developed ICT system which can be reliable at least 90 percent of the time.

This paper aims to shed light on the issues that India's educational system is facing as a result of the COVID-19 crisis by sharing firsthand experiences and research pertaining to the struggles faced by both faculty and students.

\section{Research Methodology}

In order to solve this problem of unavailability of online education during COVID-19 in a low-income school in a suburb of a big city, design thinking methodology was used to understand the issues and provide sustainable solutions. Design thinking is defined as a process for problem solving by which one uses observational skills, empathy, and a hands-on approach [3]. It involves immersing oneself into the environment to get a feel for the lives of the people who have the problem that needs to be fixed. By using the design thinking approach to problem solving, one is able to empathize with the victims/target audience and keep them as the focus of the solution. For example, it has been suggested that design thinking would be a beneficial practice to use in policymaking, since focusing on the people 
that will be impacted during the policymaking process could ensure its success and the contentment of the population with the policy. By looking at key strategies of design thinking such as environmental scanning, participant observation, and open-to-learning conversation [11], it can be seen how using design thinking would allow for engagement with the public during the process of creating and passing legislation and other policies, which should be a vital part of any policy.

Another example of design thinking being used to solve real-world problems is detailed by [9]. Their book highlights 10 different instances of design thinking being used to solve all kinds of problems, from redesigning customer contact centers at Toyota to changing the way meals at a restaurant are produced for the elderly. Through all these instances, the authors of the book found overwhelmingly positive results after design thinking was used to solve the problems. The customer care center at the Toyota branch in Torrance, California was not as efficient as it could have been. Customers had to wait for up to forty minutes just to ask a question to the staff. The leader of the branch, Elaine Matsuda, decided that the problem may not be the customers, but the employees themselves. To fix the problem, Matsuda gathered the employees and directly addressed them, asking what they felt would be the best solution to the problem. The employees then explained that it was hard to reach all the customers and answer all their questions within an adequate amount of time. Knowing this, Matsuda reached out to Toyota (and Lexus and Scion), who were sharing the branch at the time, and they helped fix the problem [9]. In this way, design thinking was used by directly addressing and empathizing with the people affected by the problem to create a solution. Another example of design thinking is Stanford University's Agile Aging project. This project aimed to make living more comfortable and accommodating for senior citizens. Members of this project would go to nursing homes and other places where elderly people lived and simply observed their way of life, while also taking note of any complaints they may have. Then, they brainstormed ideas on how to fix the complaints or make their current way of living better [8]. Once again, Agile Aging is a perfect example of design thinking by taking a human-centric, emphatic approach to a problem to come up with a solution inspired by the grievances of the victims.

Design thinking does, however, have both advantages and disadvantages. One advantage is that it improves communication and collaboration skills, leading to more effective and nuanced problem-solving techniques. Another advantage is that it allows people to be successful in life, as design thinking as a technique and the key strategies (such as 
collaboration, interviewing, problem-solving, critical thinking, and many more) used within it can be used almost every day in the workplace. By having people engage in design thinking, they can learn these skills that can be used to solve other problems. Additionally, design thinking gives people a heightened sense of accomplishment and more confidence in their abilities since they get engaged in the complete problem-solving process and experience a hands-on approach to finding solutions. On the other hand, one major disadvantage is that it takes a lot of time to go through the whole process. Giving the time and attention to communicate with each person affected by the problem, while also devoting time towards forming and executing a solution can delay the process for a long time, even though the end result may be unique and acceptable by all involved [23]. Even so, the benefits of using design thinking to problem-solve easily outweigh the detriments and the amount of time it takes to go through this thorough process.

Design thinking methodology was utilized to engage with faculty in a suburban low-income school in a major metropolitan city with over 25 million people in India. Design thinking was employed to engage with the faculty and empathize and understand the issues that were hindering online education at the school. In this school, about 90 instructors were responsible for over 4,500 students. The school caters to the lower income population and offers programs for children who cannot afford expensive education. Parents of these students were essentially blue collared workers earning daily wages by selling vegetables and fruits at the local market. The school offers programs from grades pre-primary through undergraduate including commerce and the sciences streams of education. Grades first to the fourth are considered as primary school, fifth to tenth grade are considered as secondary school, grades eleventh and twelfth are considered as junior college and degree college is the three-year undergraduate program. They also offer vocational training for students. Since March 2020, students were unable to attend face to face class because of COVID-19 and the teachers and the school was not equipped to teach remotely because of lack of instructor training and technology. There was an urgency to create solutions since the students were being affected.

Solutions that were faculty and student centric and iterative in nature were sought. Faculty were first invited to an introductory lecture via a conferencing facility such as google meet to discuss the essentials of online instruction. Topics included the need of online platforms, differences between face-to-face and online instruction, differences between synchronous and asynchronous teaching, process of recording lectures, online communication with students and online grading. Faculty were then provided with a pre-training survey to understand their 
attitude towards online education and their living environment with respect to internet connectivity, availability of computers and their technology skillset. Information regarding their annual family income to understand the instructors' affordability to buy technology and availability of a quiet space while communicating with students was also deemed important.

Next, based on the grades that the faculty taught, the 90 faculty were divided into 8 groups. They were divided into pre-primary, primary, secondary, vocational, junior college-science, junior college-commerce, degree college-science, and degree college-commerce groups. Depending on the number of faculty instructing each grade, some groups had 8 while some had 10 faculty. These groups were created since it was assumed that the issues faced by each set of faculty would be different. For example, as expected, pre-primary students are very different compared to degree college students and so are their needs. Pre-primary students, primary and some secondary school students might not own phones, and technology and would have to depend on adults for access to technology while it was assumed that the degree college students might own or have access to technology. So, it was important to host separate discussions with each group. Think tank sessions were created for each group to understand the problems associated with each group. Each think tank included a champion and 2-3 faculty selected by the group. In all there were 8 think tanks. The think tanks were responsible for representing their individual groups and sharing their ideas to find solutions. The think tanks were also responsible to train the remaining members of their group with any training they might receive. These think tanks are purposely kept small since they needed to be manageable for discussion and training purposes. Each think-tank was posed with 5 questions regarding online teaching: 1 What are your struggles while teaching online? 2. Think of a situation when you struggle while teaching online. What are the possible causes for your struggles? 3. What are you doing to engage with students online, 4. What features, and components would you like to use if an online platform was provided to you and 5. Give references of tools/sites that you use for online teaching. The results of the pre-training survey and think tank discussions were collated to finally provide sustainable solutions for online education at this school.

\section{Discussion}

The results of this design thinking process were very interesting. This process helped us to immerse into the instructor's environment to understand what their lives were like and what 
their experience/view on technology was. It was easy to empathize with their situation, as it was noticeably obvious that many of these teachers were not very proficient in educational technologies and had been thrust into the world of technology all of a sudden with their jobs at stake. Pre-training survey results showed that approximately $60 \%$ of the faculty did not own a laptop and/ or desktop at home and did not have resources to buy one in the near future. Many of the faculty did not have functioning knowledge of Word, Excel or PowerPoint either. Further discussions during the think tank sessions revealed that since many of the students especially in the pre-primary, primary and secondary schools came from a low-income neighborhoods: their parents could not afford a phone, let alone a smart phone. Internet connectivity was another obstacle in the process as well. These were major hindrances in reaching the students. Teachers would write the teaching material using pen and paper, take pictures of the handwritten material and send them to the students via WhatsApp. The students would in turn print the documents, complete the assignments using pencil, take pictures and return their assignments via WhatsApp. This was a cumbersome process and student participation was very low. Considering that each class had over 60 students, the flow of messages was immense. Since many students did not possess a smart phone, all students could not participate in this process. In addition, since many teachers who did not possess computers (laptops/desktops), they were creating PowerPoints and voice notes on smart phones and distributing them to the students. Finally, they would make groups on WhatsApp and conduct voice conferencing with the students to explain the material. As you may imagine, all this was a very tedious process. On a brighter note, discussions revealed that a larger percentage of students in the high school and degree college had better internet connectivity and smartphone availability which made interaction slightly easy.

During the discussion, it was also realized that faculty were using several freely available online resources to assist themselves and their students in their educational pursuits. Most of the educational resources are free and/or nominally charged. Some of the popular online resources are: Byju, Vedantu, Diksha app, Khan Academy, Home revise, Navneet e- digest, E-vidya, E-Pathashala and E- Balbharti. They have audio and video capabilities, and while many are specific for certain grades, others provide educational material for all grades.

Grounded on the information generate during the discussions in the think tanks, it was decided that the school would choose a common platform of google classroom to interact and communicate with the students who had the Internet connectivity and access to the required technology. Further, based on the discussions, it was decided that the faculty and champions 
in the different think tank groups would be trained to use common educational programs such as google classroom, Microsoft Word, Microsoft Excel and PowerPoint in order to be effective in teaching the students. Since many of the faculty did not possess laptops/desktops, they participated in the training using their smart phones. In short, they used google classroom, Microsoft Excel and PowerPoint on their mobile phones. This allowed them to make the transition into a virtual classroom with at least some knowledge about different ways they could incorporate these tools. They learned how to create Google Classrooms and have their students join with their email, as well as schedule virtual classes on Google Meets and create tests and quizzes. They were taught how to use PowerPoint to create slideshows for each of the lessons they wanted to teach, using animations, fonts, backgrounds, text boxes, and other features. They learned how to use Excel to enter in grades for the students in their class as well as a couple of the shortcuts for entering in the data faster. Finally, they were trained in the basics of Word, mainly for creating more nuanced assignments and just to know how to use it in everyday life. The think tank faculty were in turn responsible to teach the other faculty in their groups on the use of google classroom, Microsoft Excel and PowerPoint. This process turned out to be extremely useful. After a couple of weeks, faculty were invited to an open forum to respond to any unanswered questions and resolve remaining technical questions.

\section{Conclusion}

This paper discussed some of the issues caused by COVID-19 in the educational sphere globally and specifically in India. Although India has a well-developed educational system, it lags in its ICT's. With low Internet connectivity and lack of affordable technology in rural India and low-income suburbs of major cities, access to education is unequally divided. This became very apparent during COVID-19. Students were unable to attend face to face classes and as a result education was suffering. We attempted to resolve this situation in a lowincome suburban school in a major metropolitan city in India using the design thinking methodology. The process was faculty and student centric. The findings of the process were as follows: more than $60 \%$ of the faculty did not possess laptops/desktops and had to be trained on their mobile phones. They did not plan to buy technology in the near future as they did not have the resources. The situation was worse for the students. Many students did not possess a smart phone, let alone a computer/laptop. They borrowed technology for the class. In many cases, if the students did possess smart phones, they did not have good internet 
connectivity. Providing consistent communication for education was a huge issue in this community. Finally, lack of affordable technology is the biggest hindrance for education in some communities in India.

\section{References}

[1] Burch, P., \& Miglani, N. (2018), Technocentrism and social fields in the Indian EdTech movement: formation, reproduction and resistance. Journal of Education Policy, 33(5), 590-616.

[2] Cecchini, S., \& Scott, C. (2003), Can information and communications technology applications contribute to poverty reduction? Lessons from rural India. Information Technology for development, 10(2), 73-84.

[3] Dam, Rikke Friis, and Teo Yu Siang (2020). What Is Design Thinking and Why Is It So Popular? The Interaction Design Foundation, www.interactiondesign.org/literature/article/what-is-design-thinking-and-why-is-it-so-popular.

[4] India: Extreme Inequality in Numbers (2019), Oxfam International, www.oxfam.org/en/india-extreme-inequality-numbers, last accessed October $13^{\text {th }} 2021$

[5] Jadhav, V. R., Bagul, T. D., \& Aswale, S. R. (2020), COVID-19 Era: Students' Role to Look at Problems in Education System during Lockdown Issues in Maharashtra, India, International Journal Research and Review, https://papers.ssrn.com/sol3/papers.cfm?abstract $\mathrm{id}=3935281$, last accessed October $13^{\text {th }}$ 2021.

[6] Kochhar, Rakesh (2021) In the Pandemic, India's Middle Class Shrinks and Poverty Spreads While China Sees Smaller Changes, www.pewresearch.org/fact$\underline{\operatorname{tank} / 2021 / 03 / 18 / \text { in-the-pandemic-indias-middle-class-shrinks-and-poverty-spreads- }}$ while-china-sees-smaller-changes $/ \% 3$ famp $=1$

[7] Kumar, C., \& Chaulia, S. (2020), Stay in India, Study in India: Higher education in the corona era.

[8] Kurokawa, Toshiaki Kurokawa (2013), Design Thinking Education at Universities and Graduate Schools." Science and Technology Trends, Quarterly Review, www.nistep.go.jp/en/wp-content/uploads/Science-Technology-Trends-Quarterly-ReviewNo.46\%EF\%BC\%8Dreport4.pdf, last accessed October $13^{\text {th }} 2021$. 
[9] Liedtka, Jeanne, Andrew King and Kevin Bennett (2013), Solving Problems with Design Thinking: 10 Stories of What Works. Columbia Business School Publishing

[10] Literacy Rate Of India 2021 || State Wise Literacy Rate (2019), Census of India 2021, censusofindia2021.com/literacy-rate-of-india-2021/, last accessed October $21^{\text {st }} 2021$

[11] Mintrom, Michael, and Joannah Luetjens (2016), Design Thinking in Policymaking Processes: Opportunities and Challenges. Wiley Online Library, onlinelibrary.wiley.com/doi/epdf/10.1111/1467-8500.12211, last accessed October $13^{\text {th }}$ 2021.

[12] Mitra, Sugata, and Vivek Rana (2001), Children and the Internet: Experiments with minimally invasive education in India. British Journal of Educational Technology 32 (2), 221-232.

[13] Nair, Sulekha (2020), Online Education Has a Mountain of Problems in India but It Can Become Accessible, Inclusive If States Are More Proactive, Firstpost, www.firstpost.com/india/online-education-has-a-mountain-of-problems-in-india-but-itcan-become-accessible-inclusive-if-states-are-more-proactive-8571541.html/amp, last accessed October $13^{\text {th }} 2021$

[14] Narasimhamurthy, N. (2014) Digital divide-access and use of new information communications technology among Indian rural females, IOSR Journal of Humanities and Social Science (IOSR-JHSS), 19(8), 35-43.

[15] Nikolopoulou, K. (2014), ICT Integration in Preschool Classes: Examples of Practices in Greece. Creative Education, Creative Education, 5 (6), 402-410. doi: $10.4236 /$ ce. 2014.56050 , last accessed October $13^{\text {th }} 2021$

[16] Oliver, R. (2002) The Role of ICT in Higher Education for the 21st Century: ICT as a Change Agent for Education. http://citeseerx.ist.psu.edu/viewdoc/download?doi=10.1.1.83.9509\&rep=rep1\&type=pdf

[17] Ozili, Peterson K, and Thankom Arun (2020). Spillover of COVID-19: Impact on the Global Economy." SSRN, 30.

[18] Rajan, M. T. (2006),Digital Learning in India: Problems and Prospects, Digital Learning, Legal Background Paper, Berkman Center for Internet and Society, Harvard Law School.

[19] Raman, Bhaskaran, and Kameswari Chebrolu (2007). Experiences in using WiFi for rural internet in India. IEEE Communications Magazine 45(1), 104-110.

[20] Saxena, Kavita (2020). Coronavirus Accelerates Pace of Digital Education in India. “COVID-19 Data Explorer." Our World in Data, 2021, ourworldindata.org/explorers/coronavirus-data- 
explorer?zoomToSelection $=$ true $\&$ country $=\sim$ OWID_WRL\&hideControls=true $\&$ Interval $=$ Cumulative \&Align $\% 2$ Boutbreaks $=$ false $\&$ Relative $\% 2 B$ to $\% 2$ BPopulation=false $\&$ Metric $=$ Confirmed $\% 2$ Bcases.

[21] Sheikh, Abu Baker, Suman Pal, Nismat Javed, and Rahul Shekhar (2021), COVID-19 Vaccination in Developing Nations: Challenges and Opportunities for Innovation, MDPI, Multidisciplinary Digital Publishing Institute, www.mdpi.com/20367449/13/2/41/htm\#B20-idr-13-00041, last accessed October $13^{\text {th }} 2021$.

[22] Siddiqui, Kalim (2020), "The Impact of COVID-19 On the Global Economy, Worldfinancialreview.com, www.researchgate.net/profile/Kalim-

Siddiqui/publication/341757096_2020 The Impact_of_Covid-

19 on the Global_Economy_WFR_May June/links/5ed249c192851c9c5e667265/2020The-Impact-of-Covid-19-on-the-Global-Economy-WFR-May-June.pdf, last accessed October $13^{\text {th }} 2021$.

[23] Sulekha, Nair (2020), COVID 19 A Wakeup Call for Indian Internet Service Providers (2020),

https://www.igauge.in/admin/uploaded/report/files/QSIGAUGECOVIDISPReportApril2 020 1606732097.pdf, last accessed October $13^{\text {th }} 2021$.

[24] Tang, Hsien-Hui and E. Hsiao (2013), The advantages and disadvantages of multidisciplinary collaboration in design education. Semantic Scholar, https://www.semanticscholar.org/paper/The-advantages-and-disadvantages-ofcollaboration-Tang-Hsiao/e84a726954b273fdc502d2b857c5277138b1c459, last accessed October $13^{\text {th }} 2021$

[25] World Population review (2020) https://www.worldpopulationreview.com , last accessed October $13^{\text {th }} 2021$. 